
http://www.era.lib.ed.ac.uk/handle/1842/1152

\title{
The Piloted Transition to Flaming in Smoldering Fire Retarded and Non-Fire Retarded Polyurethane Foam
}

\author{
Olivier M. Putzeys and A. Carlos Fernandez-Pello* \\ University of California Berkeley, Berkeley, CA, 94720, USA \\ Guillermo Rein \\ University of Edinburgh, Edinburgh, EH9 3JL, UK \\ and \\ David L. Urban \\ NASA Glenn Research Center, Cleveland OH, 44135, USA
}

\begin{abstract}
The piloted transition from smoldering to flaming, though a significant fire safety concern, has not been previously extensively studied. Experimental results are presented on the piloted transition from smoldering to flaming in non-fire retarded (NFR) polyurethane foam and the fire retarded polyurethane foam Pyrell ${ }^{\circledR}$. The samples are small blocks, vertically placed in the wall of an upward wind tunnel. The free surface is exposed to an oxidizer flow and a radiant heat flux. The smolder product gases pass upwards through a pilot. The experiments on NFR foam show that the smolder velocity and peak smolder temperature, which increase with the oxygen concentration and heat flux, are strongly correlated to the transition to flaming event, in that there are minimum values of these parameters for transition to occur. The existence of a minimum smolder velocity for ignition supports the concept of a gaseous mixture reaching a lean flammability limit as the criterion for the transition to flaming. To compensate for the solid- and gas-phase effects of the fire retardants on the piloted transition in Pyrell, it was necessary to increase the oxygen concentration and the power supplied to the smolder igniter and the pilot. The piloted transition is observed in oxygen concentrations above $17 \%$ in NFR foam, and above $23 \%$ in Pyrell. The results show that although Pyrell is less flammable than NFR foam, it is still susceptible to smoldering and the piloted transition to flaming in oxygen-enriched environments, which is of interest for special applications such as future space missions.
\end{abstract}

Keywords: smoldering, transition to flaming, piloted ignition, polyurethane foam, fire retardants

\footnotetext{
* Corresponding author. E-mail: ferpello@ me.berkeley.edu, 6105A Etcheverry Hall, Department of Mechanical Engineering, University of California Berkeley, 94720. Phone: (510) 643-5282, Fax: (510) 642-1850.
} 


\section{Introduction}

Smoldering is a slowly propagating, low temperature, heterogeneous combustion reaction in which oxygen directly attacks the surface of a fuel [1]. Porous, open-celled materials such as flexible polyurethane foam are especially well suited to support smoldering due to their high surface area per unit volume, self-insulating properties, and permeability for oxidizer transport. From a fire safety perspective, smoldering is a significant concern, as $25 \%$ of residential fire deaths in the United States are caused by fires originating from smoldering smoking materials [2]. A smolder reaction can be initiated by a heat source too weak to directly produce a flaming reaction [3-5] and releases toxic and flammable gases such as carbon monoxide, various heavy hydrocarbons and large oxygenated molecules [6,7].

An important aspect of smoldering is its transition to flaming since this process can quickly lead to a large-scale fire. Several works have studied the spontaneous transition from smoldering to flaming, whereby the smolder reaction supplies the gaseous fuel and the heat to trigger a gas-phase ignition [812]. However, very little fundamental work has been done on the piloted ignition of the gaseous products of smoldering [13]. This scenario presents another significant fire risk when a spark or high-temperature heat source is present in the vicinity of a material prone to smolder. Furthermore, the piloted transition from smoldering to flaming is likely possible under a wider range of external conditions (oxygen concentrations, oxidizer flow velocities, and external heat fluxes) than the spontaneous transition from smoldering to flaming.

This study seeks to help fill the current gap in the flammability testing of porous materials with regard to their ability to smolder and undergo transition to flaming. Current test methods used to assess the flammability of solid materials, such as the Cone Calorimeter [14], the LIFT apparatus [15], and the Fire Propagation Apparatus [16], allow the determination of the critical (minimum) heat flux for ignition for a given material, by using a pilot to ignite the pyrolysis vapors released from a radiatively heated solid. However, these methods are not designed to initiate a smolder reaction in a sample, and therefore would have to be modified to test the piloted transition from smoldering to flaming.

The current study is part of a larger NASA-sponsored program to study the transition from smoldering to flaming in environmental conditions encountered in spacecraft facilities, i.e. microgravity, low velocity gas flows and a range of oxygen concentrations. An additional goal of the research is to investigate the effects of fire retardants on the transition to flaming. Therefore, both fire retarded and non-fire retarded polyurethane foams are tested. The fire 

http://www.era.lib.ed.ac.uk/handle/1842/1152

retarded foam chosen for this study was Pyrell ${ }^{\circledR 1}$ because it is currently one of the few materials allowed for equipment stowage protection in the NASA Space Shuttles and the International Space Station [17]. For future extended space flights, NASA is considering using elevated spacecraft oxygen concentrations in order to lower the total pressure (by reducing the nitrogen partial pressure) [18]. In a recent report, the NASA Exploration Atmospheres Working Group has recommended that the lunar and Mars landers and surface habitats operate at $32 \%$ oxygen and $55 \mathrm{kPa}$ [19]. In practice, there are fluctuations around the nominal oxygen concentration; for the Mars mission the control range is expected to be $+/-2 \%$. Clearly, the flammability of Pyrell in oxygen-enriched environments needs to be examined.

To date, there has been very little work published on the flammability of Pyrell foam. Putzeys et al. [10] investigated its spontaneous (unpiloted) transition from smoldering to flaming. It was found that Pyrell undergoes a weak smoldering reaction that requires significant assistance in the form of external heating and elevated oxygen concentrations. The spontaneous transition was observed in high-density Pyrell at oxygen mole fractions of 0.35 and above, and in low-density Pyrell at oxygen mole fractions of 0.40 and above.

Hshieh et al. [17] subjected Pyrell to cone calorimeter experiments in 21\% oxygen, and found that the critical heat flux for ignition (by spark igniter) was 27 $\mathrm{kW} / \mathrm{m}^{2}$ [17]. When exposed to a radiant heat flux of $26 \mathrm{~kW} / \mathrm{m}^{2}$ in $21 \%$ oxygen, Pyrell smoldered, but the gases were not ignited by the pilot within $10 \mathrm{~min}$. Upon removal of the heat source the smolder reaction quickly extinguished. The same study also found that in $30 \%$ oxygen and $70.3 \mathrm{kPa}$, Pyrell fails the NASA Upward Flame Propagation Test (NASA STD-6001 Test 1) because the flame spreads up the entire sample length.

Levchik and Weil [20] compiled a comprehensive review of the many types of fire retardants currently used in flexible polyurethane foams. The most common fire retardants are phosphorus-containing additives and halogenphosphorus-containing additives such as TDCPP, which acts in both the condensed and vapor phases. In the solid phase, a phosphorus-containing carbonaceous layer grows between the flame and the pyrolysis zone, acting as a barrier for the transfer of heat and fuel [21]. In the gas phase, the vaporized TDCPP dilutes the fuel vapors to reduce the fuel oxidation rates, therefore hindering gas-phase ignition and flaming [22]. Halogen-phosphorus-containing additives also inhibit ignition and flaming by radical scavenging: the decomposition of halogen-phosphorus additives produces both halogen radicals and phosphorus compound radicals that scavenge $\mathrm{OH}^{*}$ and $\mathrm{H}^{*}$ radicals, which can otherwise react in highly exothermic flaming [23].

\footnotetext{
${ }^{1}$ Pyrell $^{\circledR}$ is a registered trademark of Foamex International, Inc., Linwood, PA, USA. Commercial trade names are used for certain products in this report for identification purposes. This use does not constitute an endorsement by UC Berkeley or the US Government.
} 
Another common fire retardant, melamine, is usually synergistic with phosphorus or halogen-phosphorus additives, and is especially useful in suppressing smoldering [20]. Bastin et al. suggested that the synergistic effect is that the TDCPP generates phosphoric acid, which promotes the conversion of melamine into thermally stable network structures such as melam, melem, and melone [24]. Dick et al. used ${ }^{1} \mathrm{H}$ NMR spectroscopy to find that the melamine additive acts in the condensed phase by promoting the formation of a rigid char at temperatures above $400^{\circ} \mathrm{C}$ [25]. Melamine is also believed to act as a heat sink, and the nitrogen content of melamine may partly end up as nitrogen gas, providing a heat sink and diluent in the gas phase [26].

The primary objective of this work is to provide a better understanding of the controlling mechanisms of the piloted transition to smoldering to flaming, a fire-ignition scenario which has received insufficient attention from the fire community. Additionally, the experiments are designed to shed light on the effects of oxygen concentration, external heat flux, and fire retardants on the piloted transition to flaming. Furthermore, this study can provide practical information about the limiting conditions for the piloted transition to flaming in both fire retarded and non-fire retarded foam.

\section{Experiment}

\subsection{Experimental Concept}

This NASA research program originally included microgravity experiments that were planned for the International Space Station, and therefore the sample size had to be limited to dimensions of $50 \times 50 \times 125 \mathrm{~mm}$ for safety and launch mass reasons. The small dimensions of the sample hinder selfsustaining smoldering, because as the sample size is decreased, the ratio of heat losses to heat generation increases [27]. It was found in previous experiments that in order to achieve a propagating smolder reaction in the current small samples, the heat losses had to be reduced with external heating in the form of guard heaters and a radiant heat flux [12].

The experimental setup is a modification of that previously used to study the spontaneous transition from smoldering to flaming $[9,10,12]$. It consists of a vertically oriented foam sample heated on three of its surfaces with guard heaters and with the fourth, free surface, exposed to a parallel forced oxidizer flow and radiant heat flux. Smolder is initiated at the bottom of the sample and the smolder reaction propagates upward in the same direction as the oxidizer flow (buoyant and forced), i.e., forward smoldering. The gases emitted from the smoldering sample mix with the duct oxidizer flow and travel upwards through the pilot. When the gas mixture at the pilot is flammable, the gases may ignite. If the gas-phase reaction is sufficiently strong, the flame will propagate upstream and engulf the sample. 


\subsection{Experimental Apparatus}

The experiments are conducted in a small vertically oriented aluminum flow duct (Fig. 1), $380 \mathrm{~mm}$ long and with a cross-sectional area of $135 \mathrm{~mm}$ by 80 $\mathrm{mm}$. The oxidizer flow entering the test section of the flow duct first passes through a settling chamber and a converging nozzle.

The sample holder is constructed of thin-walled $(0.75 \mathrm{~mm})$ brass sheets insulated with Fiberfrax ${ }^{\mathrm{TM}}$, with a central cavity to contain the porous fuel sample (50 $\mathrm{mm} \times 50 \mathrm{~mm}$ cross section and $125 \mathrm{~mm}$ long), and the igniter holder assembly. The outer surfaces of the back and side walls of the sample holder each have a guard heater (maintained at $200{ }^{\circ} \mathrm{C}$ ) independently controlled by a Minco ${ }^{\circledR}$ temperature controller.

An infrared radiant strip heater (Research Inc. Model 4184) is mounted opposite the sample holder in the vertical wall of the flow duct and supplies a radiant heat flux perpendicular to the sample surface. For the experiments on NFR foam, the radiant heat flux was varied between 7.25 and $8.75 \mathrm{~kW} / \mathrm{m}^{2}$. However, for the tests on Pyrell, the radiant heat flux was varied between 4.5 and $5.5 \mathrm{~kW} / \mathrm{m}^{2}$. The upper limit of the heat flux range for each foam was determined to be highest heat flux that would not cause pyrolysis on the free surface of the samples. In this experiment the purpose of the radiant heater is not to initiate a reaction, but to supply additional heat to the sample (simulating a larger sample or an external heat source) and counter the convective heat losses on the free surface. The difference in the critical heat flux for pyrolysis could be due to the grey Pyrell having a higher absorptivity than the light-blue non-fire retarded foam. The lower heat fluxes were found to be the lowest at which the samples could achieve a sustained smolder reaction.

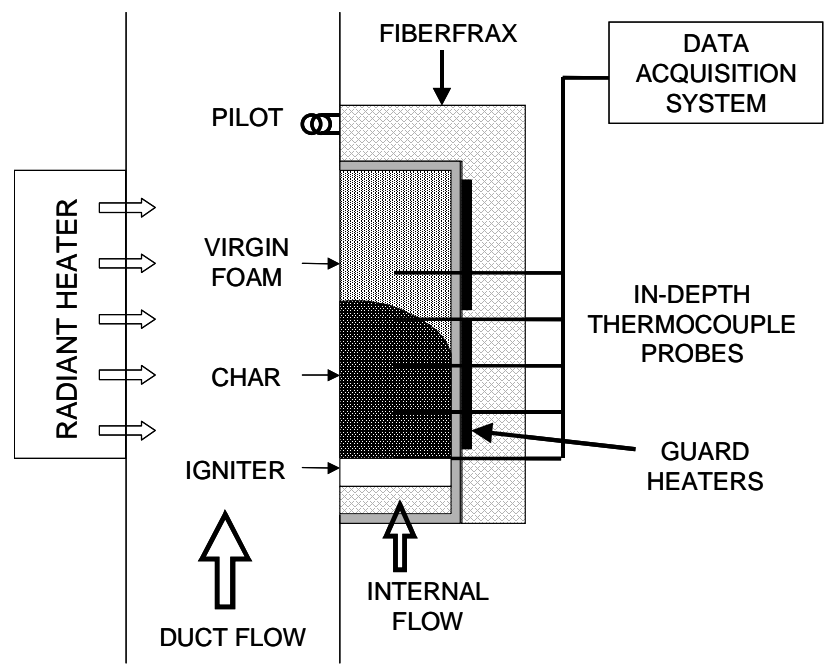

Figure 1. Schematic of the apparatus 
In order to initiate the smolder reaction, the bottom face of the sample is in contact with an electrically heated ceramic honeycomb igniter of area $50 \mathrm{~mm}$ by $50 \mathrm{~mm}$. The igniter power was set to the optimal value for smolder ignition found by preliminary testing on each foam: $23 \mathrm{~W}$ for the NFR foam and $115 \mathrm{~W}$ for the Pyrell foam. The bottom face of the igniter is insulated with a layer of Fiberfrax ${ }^{\mathrm{TM}}$ of thickness $15 \mathrm{~mm}$. During the tests, there is a forced flow of oxidizer through the Fiberfrax ${ }^{\mathrm{TM}}$ and the igniter, and into the fuel sample at a flow rate of $13.4 \mathrm{~cm}^{3} / \mathrm{s}$, which was determined to be the optimal internal flow rate for smolder initiation and propagation from previous testing.

The duct oxidizer flow is controlled using two identical sets of critical flow nozzles, and was set to $0.5 \mathrm{~m} / \mathrm{s}$ for the tests on NFR foam. However, preliminary testing showed that a smoldering reaction was very difficult to ignite in Pyrell for duct flow velocities above $0.15 \mathrm{~m} / \mathrm{s}$ due to excessive convective heat losses. Therefore, the duct flow velocity was set to $0.15 \mathrm{~m} / \mathrm{s}$ for the tests on Pyrell. The internal oxidizer flow through the igniter is controlled using mass flow controllers. Oxygen is added to air to achieve the enriched oxygen concentrations, and nitrogen is added to air to achieve sub-atmospheric oxygen concentrations. The oxygen mole fraction is varied between 0.15 and 0.35 .

The pilot consists of a coiled Nichrome (80\% Nickel/ $20 \%$ Chromium) wire with a resistance of $5.27 \mathrm{ohms} / \mathrm{m}$. The entire coil is $45 \mathrm{~mm}$ long and consists of seven coils of $7 \mathrm{~mm}$ diameter. The pilot's axis is located $15 \mathrm{~mm}$ above the top edge of the fuel sample and $5 \mathrm{~mm}$ from the flow duct wall. The pilot covers the entire species boundary layer, in order to remove the pilot's transverse location as a parameter of the problem. The vertical location of the pilot was chosen to be as close to the sample as possible while providing negligible direct heating to the sample. For the tests on the NFR foam, the pilot is supplied with $8.8 \mathrm{~A}$ of current. However, preliminary tests on Pyrell showed that it was necessary to increase the pilot current to $10 \mathrm{~A}$ in order to achieve a piloted transition to flaming; therefore 10 A was used for the Pyrell tests.

To track the progress of the smolder front and observe the transition to flaming, five type-K thermocouples are located along the centerline of the sample at distances from the igniter/fuel interface of: 0, 20,40,60, and $80 \mathrm{~mm}$. The thermocouples are $0.84 \mathrm{~mm}$ diameter sheathed grounded probes, inserted through the back of the sample.

Two tests were run using an ENERAC ${ }^{\mathrm{TM}}$ (Energy Efficiency Systems, Model 3000) gas analyzer to measure the percentage of $\mathrm{CO}$ and $\mathrm{CO}_{2}$ at the pilot. The sampling probe was placed directly below the pilot. The sensitivity of the gas analyzer is $1 \mathrm{ppm}$ for $\mathrm{CO}$ and $0.1 \%$ for $\mathrm{CO}_{2}$.

The non-fire retarded (NFR) foam used in the experiments is a flexible, open-celled polyurethane foam of density $26.5 \mathrm{~kg} / \mathrm{m}^{3}$. In addition, two different versions of the fire-retarded foam Pyrell were tested: high-density Pyrell (64.0 $\left.\mathrm{kg} / \mathrm{m}^{3}\right)$ and low-density Pyrell $\left(35.3 \mathrm{~kg} / \mathrm{m}^{3}\right)$. Both foams achieved the top rating of HF-1 for the UL-94 flame resistance test. Foamex does not provide data on the 

http://www.era.lib.ed.ac.uk/handle/1842/1152

type or amount of fire retardants used in Pyrell because that information is proprietary. However, the Material Safety Data Sheet (MSDS) for Foamex's polyurethane foams states that their fire retarded foams may release hydrogen chloride, hydrogen bromide, hydrogen fluoride or phosphoric acid depending on the fire retardant additive [28]. The Foamex Technical Products catalog describes the flame-resistant behavior of Pyrell in air: "When flame is applied, Pyrell intumesces. The surface chars, tending to form a protective shield between the flame and the foam underneath. This carbon char has low thermal conductivity and high oxidation resistance" [29]. This would be indicative of halogen-phosphorus additives, which are known to promote the growth of a phosphorus-containing carbonaceous layer between the flame and the pyrolysis zone, acting as a barrier for the transfer of heat and fuel [21]. It therefore seems likely that Pyrell includes halogen-phosphorus-containing fire retardants, which are known to act both in the solid phase and the gas phase [20].

\subsection{Experimental Procedure}

At the beginning of each test, the duct and internal flows are set, the radiant heater is turned on, and the guard heater temperature controllers are turned on. When the guard heaters reach their set-point temperature, the igniter is activated. For the experiments on Pyrell, the pilot was activated at the same time as the igniter. For the experiments on NFR foam, in order to measure the steady smolder velocity, the pilot activation was delayed until the smolder reaction had propagated through roughly two-thirds of the sample height. This was implemented by activating the pilot when the temperature at $80 \mathrm{~mm}$ passed 350 ${ }^{\circ} \mathrm{C}$. In the few tests where the temperature at $80 \mathrm{~mm}$ did not reach $350{ }^{\circ} \mathrm{C}$ (weak smolder propagation), the pilot was activated when the thermocouple at $80 \mathrm{~mm}$ reached its peak temperature. If piloted ignition occurred, the flame was extinguished with a jet of carbon dioxide. If the smolder reaction reached the top of the sample without a piloted ignition event, the test was stopped.

\section{Results}

\subsection{Non-Fire Retarded Foam Results}

A series of tests was conducted on the NFR foam at varying oxygen concentration and radiant heat flux. The results of these experiments, in terms of whether or not a piloted transition to flaming occurred, are shown in Table 1. For the upper heat flux, the piloted transition to flaming was observed at oxygen mole fractions as low as 0.17. For the middle heat flux, the transition was observed for oxygen mole fractions of 0.21 and above. For the lower heat flux, the transition was observed for oxygen mole fractions as low as 0.23. 

http://www.era.lib.ed.ac.uk/handle/1842/1152

A characteristic temperature history of a test that underwent a piloted transition to flaming is shown in Fig. 2. The test conditions were 0.21 oxygen mole fraction and $8.0 \mathrm{~kW} / \mathrm{m}^{2}$ radiant heat flux. The temperature at the igniter/fuel interface $(0 \mathrm{~mm})$ rises when the igniter is activated at $340 \mathrm{~s}$. The temperature traces of the thermocouples at 20,40 and $60 \mathrm{~mm}$ show the forward propagation of the smolder reaction. When the thermocouple at $80 \mathrm{~mm}$ passes $350{ }^{\circ} \mathrm{C}$, at $1050 \mathrm{~s}$, the pilot is activated. Separate testing using a thermocouple on the pilot have shown that the pilot takes approximately $20 \mathrm{~s}$ to reach its maximum temperature. At $1073 \mathrm{~s}$, the temperatures at all five thermocouples jump sharply, indicating a piloted transition to flaming event. The flame is quickly extinguished with a jet of carbon dioxide.

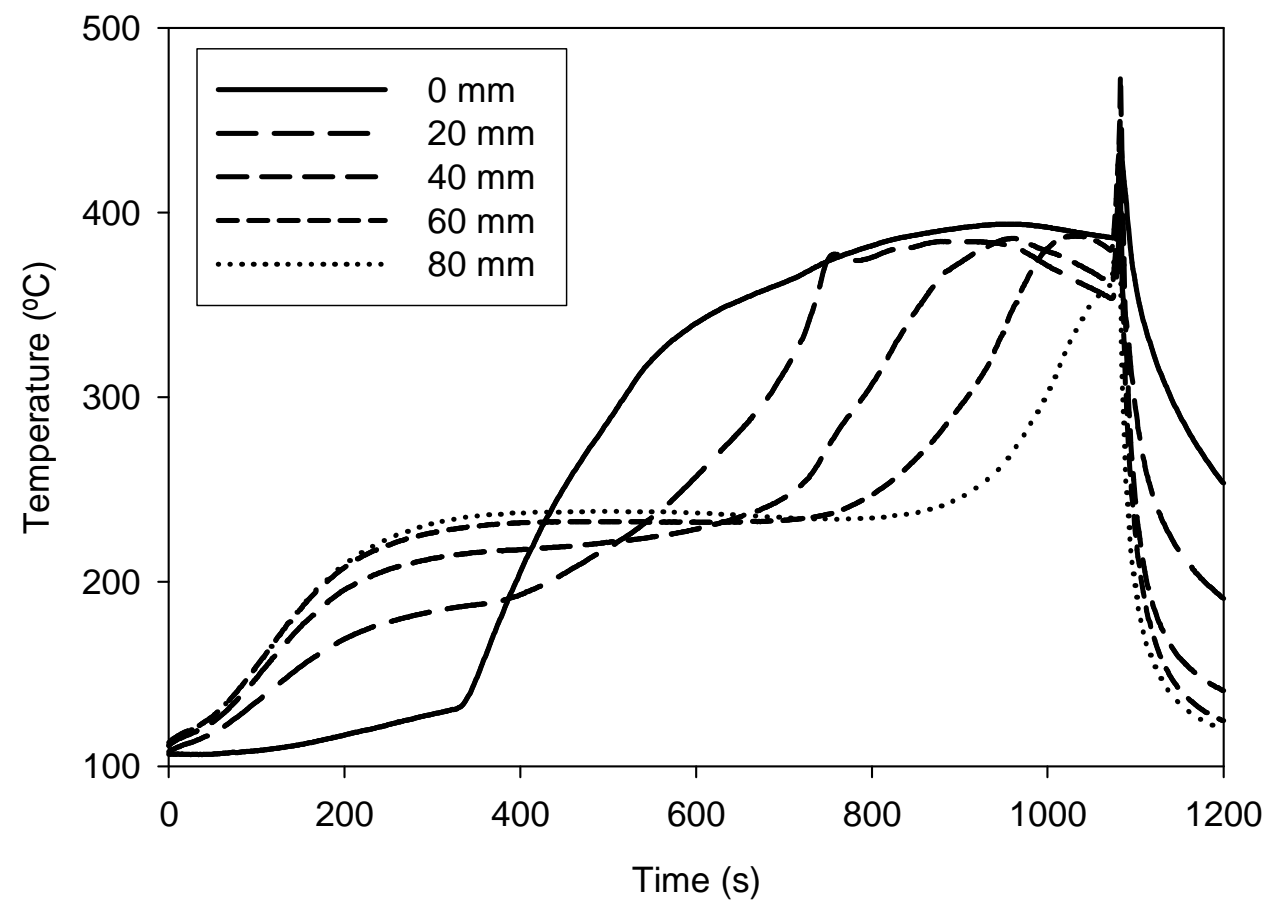

Figure 2. Characteristic temperature history of smoldering and piloted transition to flaming in non-fire retarded foam. The legend indicates the thermocouple heights above the igniter.

The thermocouple data from these experiments is used to provide two measures of the intensity of the smolder reaction: peak smolder temperature and the smolder propagation velocity. Fig. 3 shows the peak smolder temperature for the NFR foam at the midpoint of the sample $(60 \mathrm{~mm})$ for each test. The data shows that as the oxygen mole fraction or the radiant heat flux are increased, the peak smolder temperature increases. Interestingly, all the data points above the dashed line represent tests that did undergo a transition to flaming, and all the points below the dashed line represent tests that did not. This suggests that for 
the NFR foam there is a minimum smolder temperature for the piloted transition to flaming. For this experimental configuration, this temperature is in the range of 360 to $365^{\circ} \mathrm{C}$.

Table 1. Results of tests on non-fire retarded foam at varying oxygen mole fraction and radiant heat flux, in terms of transition to flaming $(\mathrm{Y})$ and no transition to flaming (N)

\begin{tabular}{|c|c|c|c|}
\hline $\begin{array}{c}\text { Oxygen } \\
\text { Mole } \\
\text { Fraction }\end{array}$ & $\begin{array}{c}7.25 \\
\mathrm{~kW} / \mathrm{m}^{2}\end{array}$ & $\begin{array}{c}8.0 \\
\mathrm{~kW} / \mathrm{m}^{2}\end{array}$ & $\begin{array}{c}8.75 \\
\mathrm{~kW} / \mathrm{m}^{2}\end{array}$ \\
\hline 0.23 & $\mathbf{Y}$ & $\mathbf{Y}$ & $\mathbf{Y}$ \\
\hline 0.21 & $\mathbf{N}$ & $\mathbf{Y}$ & $\mathbf{Y}$ \\
\hline 0.19 & $\mathbf{N}$ & $\mathbf{N}$ & $\mathbf{Y}$ \\
\hline 0.17 & & $\mathbf{N}$ & $\mathbf{Y}$ \\
\hline 0.15 & & & $\mathbf{N}$ \\
\hline
\end{tabular}

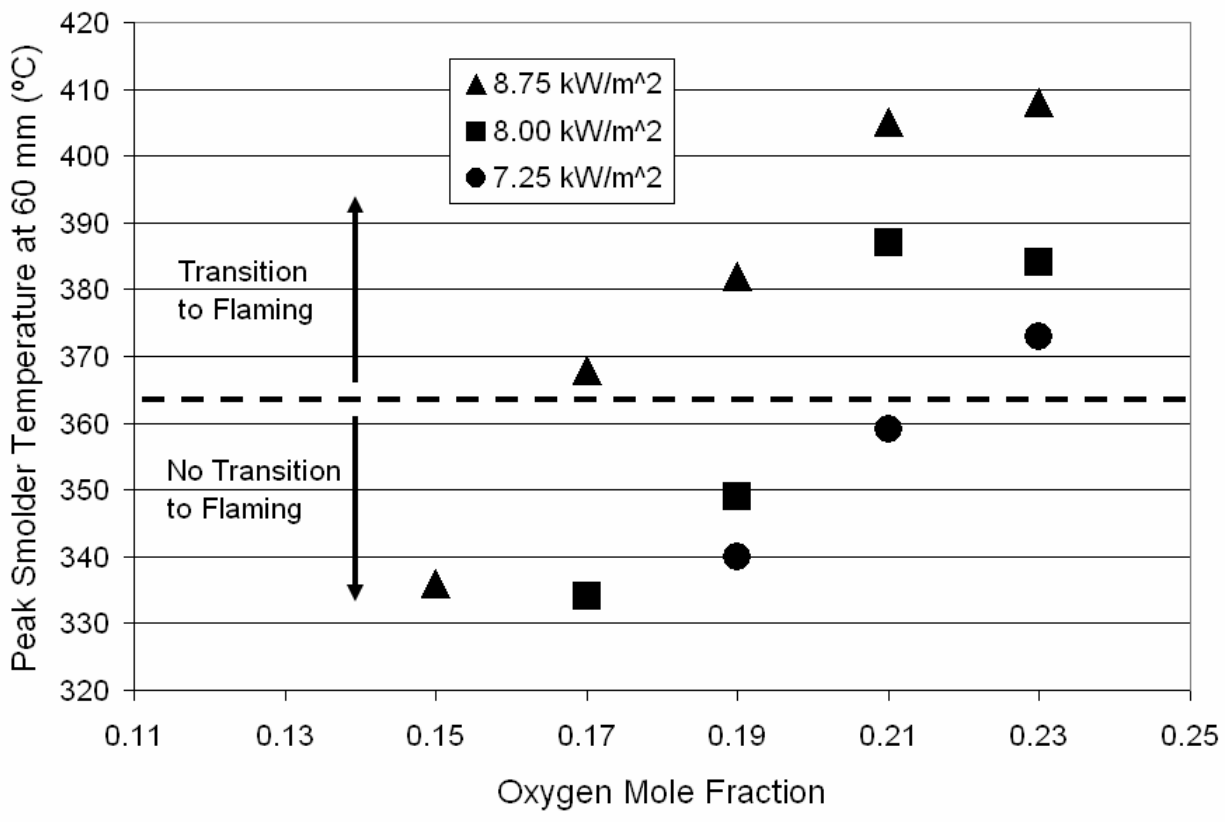

Figure 3. Peak smolder temperature at $60 \mathrm{~mm}$ versus oxygen mole fraction, at three different heat fluxes, for the non-fire retarded foam.

Fig. 4 shows the smolder velocity in the NFR foam for varying oxygen mole fraction and radiant heat flux. The velocities were calculated assuming that the arrival of the smolder front corresponds to a temperature of $300{ }^{\circ} \mathrm{C}$. The velocities were averaged over the central region of the sample (from 40 to 80 $\mathrm{mm}$ ) where the reaction is less influenced by the igniter or the end effects. The data shows that as the oxygen mole fraction or the radiant heat flux is increased, the smolder velocity increases. It appears that there is also a minimum smolder 
velocity for the piloted transition to flaming. For this experimental configuration, this velocity is in the range of 0.18 to $0.19 \mathrm{~mm} / \mathrm{s}$.

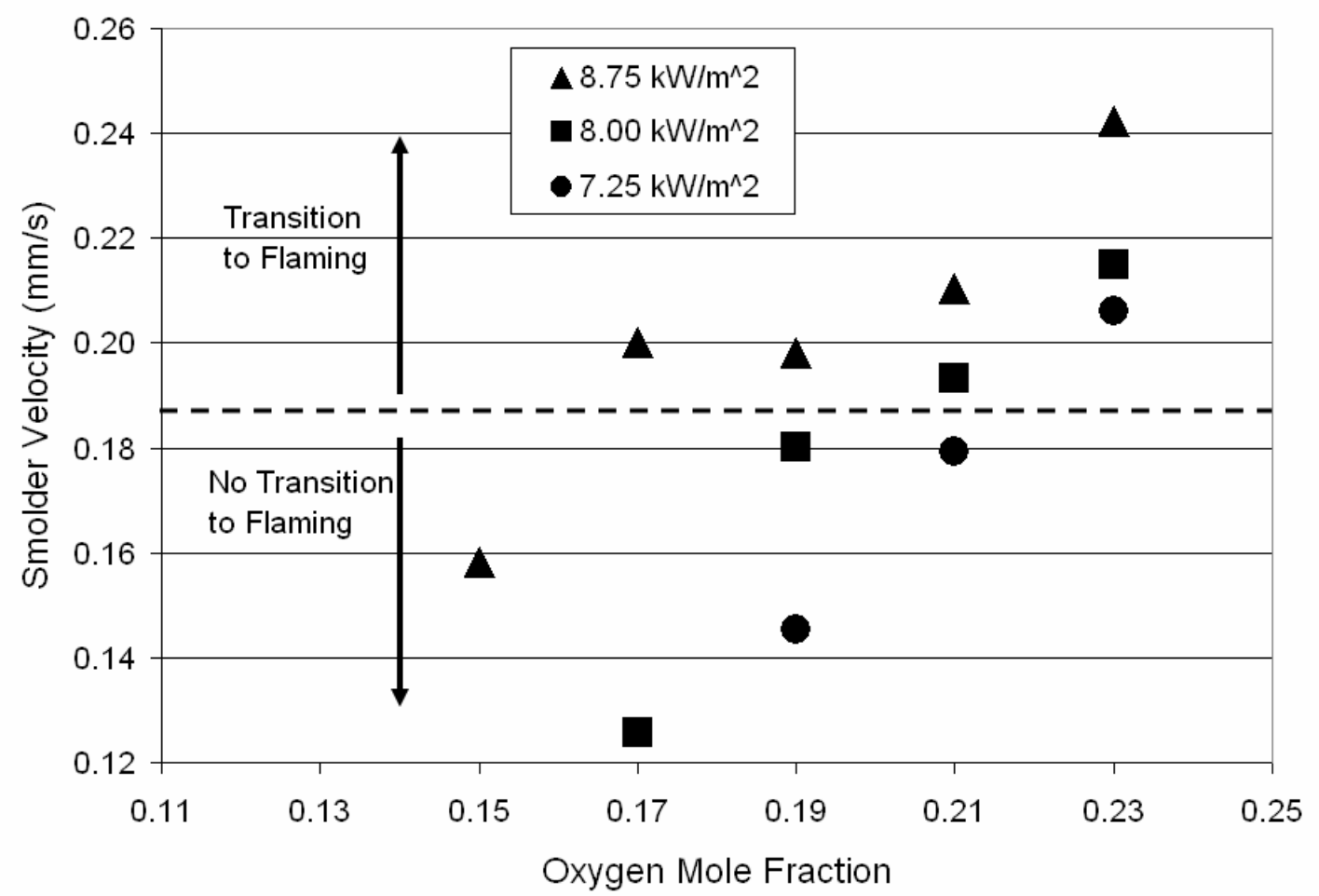

Figure 4. Smolder velocity versus oxygen mole fraction, at three different heat fluxes, for the non-fire retarded foam.

Fig. 5 shows the correlation between the smolder velocity and the peak smolder temperature for the NFR foam, for tests at varying oxygen mole fraction and radiant heat flux. The minimum values of smolder velocity and peak smolder temperature for the transition are marked with dashed lines, demarcating the regions of transition to flaming, and no transition to flaming. Fig. 5 shows the strong correlation between velocity and temperature during smoldering propagation, and indicates that the minimum velocity for the transition corresponds well with the minimum temperature. 


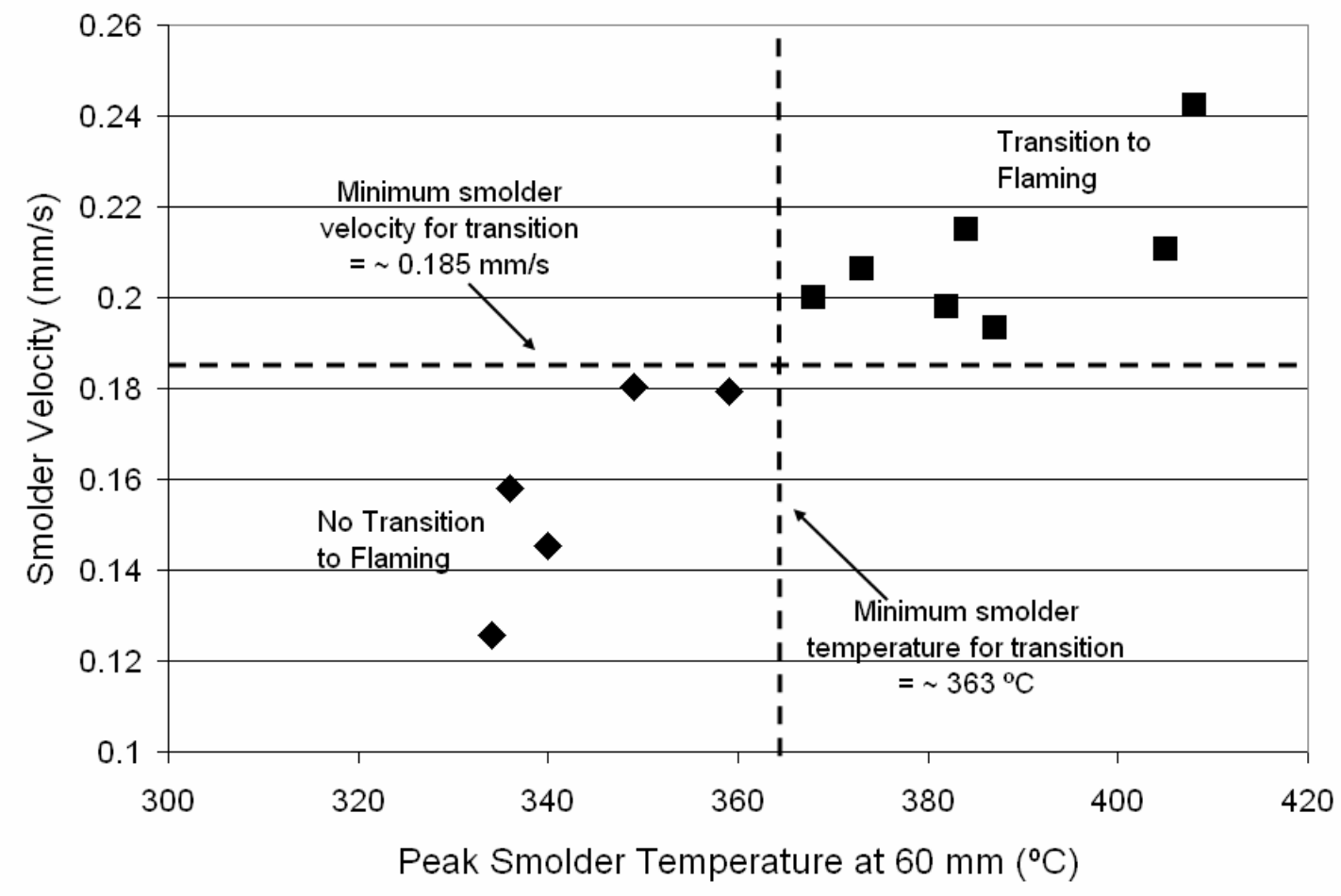

Figure 5. Smolder velocity versus peak smolder temperature at the sample midpoint, for tests at varying oxygen mole fraction and radiant heat flux, for the non-fire retarded foam.

\subsection{Fire Retarded Foam Results}

Tests were also performed on high-density and low-density Pyrell at varying oxygen concentration and radiant heat flux. The results of these experiments, in terms of whether or not a piloted transition to flaming occurred, are shown in Table 2. Table 2 shows that high-density and low-density Pyrell exhibited similar behavior in terms of the threshold values of oxygen concentration and radiant heat flux for the transition to flaming. All the tests at 0.25 oxygen mole fraction and above underwent transition to flaming, while none of the tests in normal air ( 0.21 oxygen mole fraction) underwent transition to flaming. At 0.23 oxygen mole fraction, only the tests at the higher radiant heat flux $\left(5.5 \mathrm{~kW} / \mathrm{m}^{2}\right)$ underwent transition to flaming. It is expected that at higher heat fluxes the piloted transition to flaming could occur in Pyrell at even lower oxygen concentrations. As mentioned earlier, experiments at higher heat fluxes lie outside the scope of this work since they initiate a strong reaction on the free surface of the sample. For the present experimental conditions, Pyrell does not exhibit steady self-sustained smoldering because the smolder reaction weakens as it propagates away from the igniter; therefore, it is difficult to measure a steady smolder velocity in Pyrell. 


\subsection{Gas Analysis}

To determine the composition of the gases involved in the piloted ignition, tests were run using the ENERAC ${ }^{\mathrm{TM}}$ gas analyzer. The gas-sampling probe was placed directly below the pilot, which was not activated for these tests. The concentrations of $\mathrm{CO}$ and $\mathrm{CO}_{2}$ were measured during smoldering of the NFR foam and low-density Pyrell. The NFR foam was tested at 0.21 oxygen mole fraction, $0.15 \mathrm{~m} / \mathrm{s}$ duct flow, and $8.0 \mathrm{~kW} / \mathrm{m}^{2}$. The low-density Pyrell was tested at 0.21 oxygen mole fraction, $0.15 \mathrm{~m} / \mathrm{s}$ duct flow, and $4.5 \mathrm{~kW} / \mathrm{m}^{2}$. The concentrations of $\mathrm{CO}$ and $\mathrm{CO}_{2}$ were found to approach steady-state values after the initiation of the smolder reaction. Table 3 shows the measured steady-state concentrations of these gases for both foams.

Table 2. Results of tests on Pyrell at varying oxygen mole fraction and radiant heat flux, in terms of transition to flaming (Y) and no transition to flaming (N)

\begin{tabular}{|c|c|c|c|c|}
\hline \multirow{2}{*}{$\begin{array}{c}\text { Oxygen } \\
\text { Mole } \\
\text { Fraction }\end{array}$} & \multicolumn{2}{|c|}{$\begin{array}{c}\text { Low-Density } \\
\text { Pyrell }\end{array}$} & \multicolumn{2}{c|}{$\begin{array}{c}\text { High-Density } \\
\text { Pyrell }\end{array}$} \\
\cline { 2 - 5 } & $\begin{array}{c}4.5 \\
\mathrm{~kW} / \mathrm{m}^{2}\end{array}$ & $\begin{array}{c}5.5 \\
\mathrm{~kW} / \mathrm{m}^{2}\end{array}$ & $\begin{array}{c}4.5 \\
\mathrm{~kW} / \mathrm{m}^{2}\end{array}$ & $\begin{array}{c}5.5 \\
\mathrm{~kW} / \mathrm{m}^{2}\end{array}$ \\
\hline 0.35 & $\mathbf{Y}$ & $\mathbf{Y}$ & $\mathbf{Y}$ & $\mathbf{Y}$ \\
\hline 0.30 & $\mathbf{Y}$ & $\mathbf{Y}$ & $\mathbf{Y}$ & $\mathbf{Y}$ \\
\hline 0.25 & $\mathbf{Y}$ & $\mathbf{Y}$ & $\mathbf{Y}$ & $\mathbf{Y}$ \\
\hline 0.23 & $\mathbf{N}$ & $\mathbf{Y}$ & $\mathbf{N}$ & $\mathbf{Y}$ \\
\hline 0.21 & $\mathbf{N}$ & $\mathbf{N}$ & $\mathbf{N}$ & $\mathbf{N}$ \\
\hline
\end{tabular}

The results in Table 3 show that Pyrell, although subjected to 5 times higher igniter power, produces lower levels of $\mathrm{CO}$ and $\mathrm{CO}_{2}$ than the NFR foam. This is likely due to the weaker smoldering reaction in Pyrell as a result of the solid-phase fire retardant effects. The fire retardants in Pyrell could act as heat sinks or alter the smolder kinetics in the solid phase to reduce the smoldering reaction rate, thereby reducing the production of $\mathrm{CO}$ and $\mathrm{CO}_{2}$.

Table 3. Measured steady-state concentrations of gases at the pilot during smoldering in non-fire retarded foam and low-density Pyrell.

\begin{tabular}{|c|c|c|}
\hline & NFR Foam & $\begin{array}{c}\text { Low- } \\
\text { Density } \\
\text { Pyrell }\end{array}$ \\
\hline $\mathrm{CO}$ & $0.4 \%$ & $0.02 \%$ \\
\hline $\mathrm{CO}_{2}$ & $1.1 \%$ & $0.5 \%$ \\
\hline
\end{tabular}




\section{Discussion}

\section{Lean Flammability Limit Criterion for the Piloted Transition to Flaming}

It is of interest to determine the conditions that lead to the piloted transition to flaming. In this regard, the present study can benefit from considering previous works on the piloted ignition of heated non-porous solids [30-32]. Numerous works on the piloted flaming ignition of solids have shown that the ignition event occurs when the mass flux of pyrolysates reaches a critical value, allowing the gaseous mixture near the pilot to surpass the lean flammability limit [33]. The following analysis of the current experimental results on NFR foam leads to the definition of a similar criterion for piloted transition to flaming of a smoldering solid. For the current process, the relevant parameter to the problem is the total mass production rate of smolder product gases, which can be related to the smolder velocity as follows:

$$
\dot{m}_{g}=U_{s m l} \rho_{f} \alpha_{s g} A_{c}
$$

where $\dot{m}_{g}$ is the mass flow rate of smolder product gases exiting the sample, $U_{s m l}$ is the smolder velocity, $\rho_{f}$ is the density of the foam, $a_{s g}$ is the fraction of solid that is converted to gas by the smolder reaction, and $A_{c}$ is the cross-sectional area of the smoldering sample. Post-test sample weighing has shown the global solidto-gas conversion fraction in forward smoldering in the NFR foam is fairly constant around 0.6 for the range of external conditions of this study. Using Eq. (1) and the minimum smolder velocity for the transition to flaming $(0.185 \mathrm{~mm} / \mathrm{s})$ obtained from Fig. 4, a critical pyrolysate mass flow rate of $7.35 \mathrm{mg} / \mathrm{s}$ is obtained. Smolder velocities greater than the minimum smolder velocity produce pyrolysate mass flow rates above the critical value, causing the gas mixture at the pilot to pass the lean flammability limit, and enabling gas-phase ignition.

For the tests on Pyrell, it was not possible to measure a steady smolder velocity and use the above approach to determine the existence of a critical pyolysate mass flow for the transition to flaming. However, it was experimentally observed that the amount of pyrolysate produced by the sample increased until the ignition of the gases near at the pilot occurred. This observation supports the concept of a lean flammability limit criterion for the piloted transition to flaming in Pyrell as well.

Smoldering combustion is generally oxygen-limited rather than kinetically limited. However, the experimental results indicate that the likelihood of a transition to flaming is correlated to the temperature at the smolder front. The relationship between the smolder temperature and the pyrolysate mass production rate can be understood by considering the solid-to-gas conversion as 
a global one-step reaction. Assume that an Arrhenius-type expression can be used in the following form:

$$
\frac{\dot{m}_{g}}{m_{0}}=Z e^{-E / R T_{s m l}}
$$

where $m_{0}$ is the initial mass of solid, $Z$ is the inverse of the characteristic time of the process, $E$ is the activation energy, $R$ is the universal gas constant, and $T_{s m l}$ is the peak smolder temperature. Rearranging Eq. (2) into logarithmic form results in the following expression:

$$
\ln \left(\frac{\dot{m}_{g}}{m_{0}}\right)=\left(-\frac{E}{R}\right) \frac{1}{T}+\ln (Z)
$$

Using Eq. (1), the reaction rate can be written as follows:

$$
\frac{\dot{m}_{g}}{m_{0}}=\frac{U_{s m l} \rho_{f} \alpha_{s g} A_{c}}{\rho_{f} A_{c} L_{c}}=\frac{U_{s m l} \alpha_{s g}}{L_{c}}
$$

where $L_{c}$ is the characteristic length (the cross-sectional side length, $50 \mathrm{~mm}$ for this experimental configuration). Using Eq. (4), the experimental values of smolder velocity and peak smolder temperature are plotted in Fig. 6. A linear trendline fits well to the experimental data, and using Eq. (3), the estimated activation energy $E$ is found to be $22 \mathrm{MJ} / \mathrm{kmol}$, and the characteristic time $1 / \mathrm{Z}$ is $7 \mathrm{~s}$. Thermogravimetric analyses have previously found the activation energy of thermal decomposition of polyurethane foam (in the temperature range of 354$378^{\circ} \mathrm{C}$ ) to be $79.9 \mathrm{MJ} / \mathrm{kmol}[34]$, which is in the same order of magnitude as the present result. The discrepancy in values could be attributed to a number of simplifications used in the above analysis including, the use of a single global pyrolysis reaction, an average smolder velocity, an overall conversion factor, $a_{s g}$, and possible differences in the chemical formulations of the polyurethane foams studied. The linear fit in Fig. 6 indicates that the Arrhenius-type expression is a good approximation for the kinetics of the solid-to-gas conversion in smoldering. In addition, this supports the experimentally observed effect of smolder temperature on the likelihood of the piloted transition to flaming. Since for smolder temperatures below $363{ }^{\circ} \mathrm{C}$, the transition to flaming did not occur, it can be inferred that below $363{ }^{\circ} \mathrm{C}$, the mass flow rate of smolder gaseous products is insufficient to surpass the lean flammability limit and produce a gasphase ignition. 


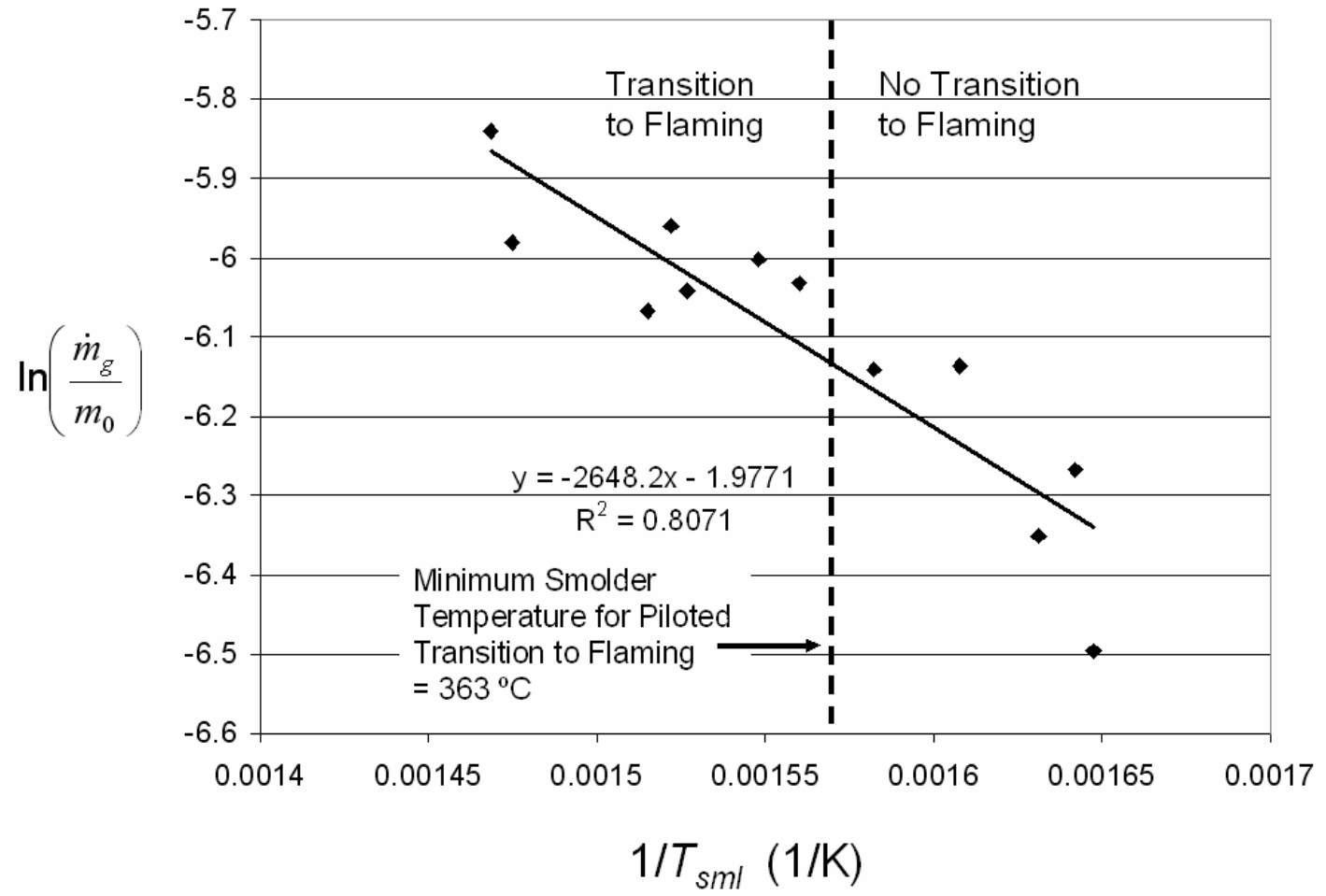

Figure 6. Plot of the reaction rate vs. the inverse of the peak smolder temperature to capture the Arrhenius behavior.

\section{Effects of Oxygen Concentration and Heat Flux}

The results in Table 1 and Table 2 show that increasing the oxygen concentration increases the likelihood of a piloted transition for both Pyrell and the NFR foam. Increased oxygen concentration increases the smolder reaction rate, thereby increasing the heat generation and raising the temperature in the solid phase, which increases the rate of pyrolysate production. Therefore, increased oxygen concentration can cause the gaseous mixture to pass the lean flammability limit, and allow the piloted transition to flaming. In addition, the gas phase reactions are also enhanced at elevated oxygen concentration, facilitating the transition to flaming.

Table 1 and Table 2 also show that increasing the radiant heat flux increases the likelihood of a piloted transition from smoldering to flaming. Increased radiant heat flux raises the temperature in the solid phase, therefore directly increasing the rate of pyrolysate production. The increased radiant heat flux also increases the smolder reaction rate, further raising the solid-phase temperature and the rate of pyrolysate production. Therefore, increased radiant heat flux can cause the gaseous mixture to pass the lean flammability limit, and allow piloted transition to flaming. 


\section{Effects of Fire Retardants}

Comparing the results of the experiments on the NFR foam and Pyrell gives insight into the effects of the fire retardants on the piloted transition from smoldering to flaming. The fire retardants in Pyrell can have a two-fold effect on the piloted transition from smoldering to flaming. First, the fire retardants can act in the solid phase to hinder the smolder reaction. Pyrell could include melamine, for example, which is believed to act as a heat sink [26] and can form into thermally stable network structures [24]. This study has confirmed that Pyrell requires significantly more external heat input in order to initiate a smolder reaction and allow a piloted transition to flaming. The power of the igniter needed to be set significantly higher for Pyrell (115 W) than for the NFR foam $(23 \mathrm{~W})$. In addition, the findings of the gas analysis that smoldering in Pyrell produces lower levels of $\mathrm{CO}$ and $\mathrm{CO}_{2}$ than smoldering in NFR foam further confirm that the fire retardants act in the solid phase to weaken the smolder reaction.

The fire retardants in Pyrell can also hinder gas-phase combustion reactions, which would further impede the piloted transition to flaming. The fire retardants probably include halogen-phosphorus-containing additives that vaporize and inhibit gas-phase reactions in two ways: dilution of the volatile fuel mixture, and scavenging of $\mathrm{OH}^{*}$ and $\mathrm{H}^{*}$ radicals in the gas phase. In order to compensate for these fire retardant effects, it was necessary to raise the pilot current from 8.8 A (approximately $810^{\circ} \mathrm{C}$, as measured with an infrared camera) as used on NFR foam, to 10 A (approximately $900{ }^{\circ} \mathrm{C}$ ). This corresponds to a $30 \%$ increase in power supplied to the pilot. Increasing the pilot power causes the gas parcel passing through the pilot to be heated to a higher temperature, thereby increasing the gas-phase reaction rates and helping to overcome the radicalscavenging and diluting effects of the fire retardants.

The solid- and gas-phase effects of the fire retardants in Pyrell raised the threshold oxygen mole fraction for the piloted transition to flaming to 0.23 , as opposed to 0.17 for NFR foam. The elevated oxygen concentrations were necessary to generate more heat from smoldering, so as to produce more pyrolysate to overcome the fire retardant effects of dilution and radical scavenging. In addition, higher oxygen concentration can help overcome the gasphase fire retardant effects by increasing the gas-phase oxidation reaction rates, enabling piloted ignition.

\section{Conclusion}

The piloted transition from smoldering to flaming, though a significant fire safety concern, has not been previously extensively studied. The experiments conducted in this work indicate that a high-temperature heat source in the vicinity of a smoldering material presents a fire hazard due to the potential 

http://www.era.lib.ed.ac.uk/handle/1842/1152

piloted ignition of the smolder product gases. Furthermore, previous experiments by the authors, using the same apparatus without a pilot, showed that the spontaneous transitions to flaming in NFR foam and Pyrell require oxygen concentrations higher than the corresponding critical oxygen concentrations observed for the piloted transition in this work [9,12]. This indicates that the presence of a pilot near a smoldering material increases the risk of a transition to flaming.

The results show that the piloted transition to flaming in a non-fire retarded (NFR) foam is dependent on the strength of the smolder reaction, which is represented by the smolder velocity and temperature. The smolder velocity and peak smolder temperature in NFR foam are found to be strongly affected by the oxygen mole fraction and radiant heat flux, and to be strongly correlated to the piloted transition to flaming event, in that there are minimum values of these parameters for ignition to take place. The existence of a minimum smolder velocity for the piloted transition supports the concept of the gaseous mixture reaching a lean flammability limit as the criterion for transition to flaming, because the pyrolysate mass production rate is proportional to the smolder velocity. A one-step Arrhenius-type expression proposed for the conversion of solid to gas in smoldering helps explain the relationship between the smolder temperature and the pyrolysate mass production, and the observed relationship between smolder temperature and the piloted transition to flaming.

The experiments have shown that the fire retardants in Pyrell can act to hinder the piloted transition from smoldering to flaming. In order to compensate for the effects of the fire retardants, it was necessary to raise the igniter power and the pilot power relative to those used for NFR foam, and to raise the oxygen concentration to above-ambient values.

The experiments have also shown that the fire retardants in Pyrell are effective in hindering smolder propagation and preventing the piloted transition to flaming in normal air. However, the results show that Pyrell is susceptible to smoldering and the piloted transition to flaming in oxygen concentrations as low as $23 \%$. These findings are of interest for the planning of future space missions and the on-going considerations to use elevated oxygen concentrations in the next generation of spacecraft. It should be noted that real-life fires generally occur under natural convection conditions and not wind tunnel conditions as used in this work. For fuel samples of the size used in this study, the effects of buoyancy are limited. At larger scales, the results may be somewhat different, but the general trends observed in this study would likely remain unchanged.

\section{Acknowledgments}

The authors would like to thank Winston Chiang, Jesse Limtiaco and Patrick Faner for their help conducting the experiments, and David Rich and Chris Lautenberger for their advice and suggestions. The authors also gratefully 

http://www.era.lib.ed.ac.uk/handle/1842/1152

acknowledge the support of the STAF engineering team at NASA Glenn Research Center, as well as NASA for funding this research under grant \#NCC 05-AA49A and the NASA Graduate Student Research Program.

\section{References}

1. Ohlemiller, T. J., Modeling of smoldering combustion propagation. Progress in Energy and Combustion Science 1985 ; 11 (4): 277-310.

2. Hall, J. R., "The Smoking-Material Fire Problem," National Fire Protection Association, Quincy, MA, 2004.

3. Anthenien, R. A. and Fernandez-Pello, A. C., Study of forward smolder ignition of polyurethane foam. Proceedings of the Combustion Institute 1998; 27: 2683-2690.

4. Walther, D. C., Anthenien, R. A., and Fernandez-Pello, A. C., Smolder ignition of polyurethane foam: effect of oxygen concentration. Fire Safety Journal 2000; 34 (4): 343-359.

5. Anderson, M. K., Sleight, R. T., and Torero, J. L., Downward smolder of polyurethane foam: Ignition signatures. Fire Safety Journal 2000; 35 (2): 131147.

6. Rogers, F. E. and Ohlemiller, T. J., Smolder characteristics of flexible polyurethane foams. Journal of Fire and Flammability 1980; 11 (1): 32-44.

7. Walther, D. C., Fernandez-Pello, A. C., and Urban, D. L., Space Shuttle based microgravity smoldering combustion experiments. Combustion and Flame 1999; 116 (3): 398-414.

8. Ohlemiller, T. J., Forced smolder propagation and the transition to flaming in cellulosic insulation. Combustion and Flame 1990; 81 (3-4): 354-365.

9. Putzeys, O. M. , Bar-Ilan, A., Rein, G., Fernandez-Pello, A. C., and Urban, D. L., The role of secondary char oxidation in the transition from smoldering to flaming. Proceedings of the Combustion Institute 2007; 31: 2669-2676.

10. Putzeys, O. M., Fernandez-Pello, A. C., and Urban, D. L., Ignition of combustion modified polyurethane foam. Journal of ASTM International 2006; 3 (3): 1-14.

11. Tse, S. D., Fernandez-Pello, A. C., and Miyasaka, K., Controlling mechanisms in the transition from smoldering to flaming of flexible polyurethane foam. Proceedings of the Combustion Institute 1996; 26: 15051513.

12. Bar-Ilan, A., Putzeys, O. M., Rein, G., Fernandez-Pello, A. C., and Urban, D. L., Transition From Forward Smoldering to Flaming in Small Polyurethane Foam Samples. Proceedings of the Combustion Institute 2005; 30: 2295-2302.

13. Babrauskas, V. Ignition Handbook. Fire Science Publishers: Issaquah, WA, $2003 ; 318$. 
O Putzeys, AC Fernandez-Pello, G Rein, DL Urban, The Piloted Transition to Flaming in Smoldering Fire Retarded and Non-Fire

Retarded Polyurethane Foam, Fire and Materials 32, pp. 485-499, 2008. http://dx.doi.org/10.1002/fam.981. Free access version at http://www.era.lib.ed.ac.uk/handle/1842/1152

14. ASTM E-1354-03, Standard Test Method for Heat and Visible Smoke Release Rates for Materials and Products Using an Oxygen Consumption Calorimeter. ASTM Fire Test Standards (1993) 968-984.

15. ASTM 1321-97a, Standard Test Method for Determining Material Ignition and Flame Spread Properties. ASTM Fire Test Standards (1997).

16. ASTM E-2058-03, Standard Test Methods for Measurement of Synthetic Polymer Material Flammability Using a Fire Propagation Apparatus (FPA). ASTM Fire Test Standards (2001).

17. Hshieh, F.-Y., Hirsch, D., and Beeson, H., Evaluation of Polyimide Foam as a Fire Barrier for Spacecraft Cushion Materials. Journal of Fire Sciences 2003; 21 (6): 485-501.

18. Lange, K. E., Perka, A. T., Duffield, B. E., and Jeng, F. F., "Bounding the Spacecraft Atmosphere Design Space for Future Exploration Missions," NASA/CR-2005-213689, 2005.

19. Campbell, P. D. and Henninger, D. L., "Recommendations for Exploration Spacecraft Internal Atmospheres: The Final Report of the NASA Exploration Atmospheres Working Group," NASA JSC-63309, 2006.

20. Levchik, S. V. and Weil, E. D., Thermal decomposition, combustion and fireretardancy of polyurethanes - A review of the recent literature. Polymer International 2004; 53 (11): 1585-1610.

21. Ravey, M., Weil, E. D., Keidar, I., and Pearce, E. M., Flexible polyurethane foam. II. Fire retardation by tris(1,3-dichloro-2-propyl) phosphate. Part B. Examination of the condensed phase (the pyrolysis zone). Journal of Applied Polymer Science 1998; 68 (2): 231-254.

22. Ravey, M., Keidar, I., Weil, E. D., and Pearce, E. M., Flexible polyurethane foam. II. Fire retardation by tris(1,3-dichoro-2-propyl) phosphate. Part A. Examination of the vapor phase (the flame). Journal of Applied Polymer Science 1998; 68 (2): 217-229.

23. Lefebvre, J., Le Bras, M., Bastin, B., Paleja, R., and Delobel, R., Flexible polyurethane foams: Flammability. Journal of Fire Sciences 2003; 21 (5): 343367.

24. Bastin, B., Paleja, R., and Lefebvre, J., Fire behavior of polyurethane foams. Journal of Cellular Plastics 2003; 39 (4): 323-340.

25. Dick, C. M., Denecker, C., Liggat, J. J., Mohammed, M. H., Snape, C. E., Seeley, G., Lindsay, C., Eling, Be., and Chaffanjon, P., Solid state $13 \mathrm{C}$ and in situ 1H NMR study on the effect of melamine on the thermal degradation of a flexible polyurethane foam. Polymer International 2000; 49 (10): 1177-1182.

26. Price, D., Liu, Y., Milnes, G. J., Hull, R., Kandola, B. K., and Horrocks, A. R., An investigation into the mechanism of flame retardancy and smoke suppression by melamine in flexible polyurethane foam. Fire and Materials 2002; 26 (4-5): 201-206.

27. Bar-Ilan, A., Rein, G., C.walther, D., Fernandez-Pello, A. C., Torero, J. L., and Urban, D. L., The effect of buoyancy on opposed smoldering. 

http://www.era.lib.ed.ac.uk/handle/1842/1152

Combustion Science and Technology 2004; 176 (12): 2027-2055.

28. Polyurethane Foam Material Science Data Sheet. March 2004. 1000 Columbia Avenue, Linwood PA 19061, Foamex International.

29. Foamex Technical Products Catalog. 2005. 1500 East Second Street, Eddystone, PA 19022, Foamex International, Technical Products Group.

30. Drysdale, D. D. and Thomson, H. E., Flammability of plastics II: Critical mass flux at the firepoint. Fire Safety Journal 1989; 14 (3): 179-188.

31. Rich, D., Lautenberger, C., Hernandez, J., and Fernandez-Pello, A. C., "Effect of environmental variables on critical pyrolysate mass flux for piloted ignition of PMMA and PP/GL composite," Mediterranean Combustion Symposium, Lisbon.

32. Zhou, Y. and Fernandez-Pello, A. C., Numerical modeling of endothermic pyrolysis and ignition delay of composite materials exposed to an external radiant heat flux. Proceedings of the Combustion Institute 2000; 28: 2769-2775.

33. Rasbash, D. J., Drysdale, D. D., and Deepak, D., Critical heat and mass transfer at pilot ignition and extinction of a material. Fire Safety Journal 1986; 10 (1): 1-10.

34. Chao, C. Y. H. and Wang, J. H., Comparison of the thermal decomposition behavior of a non-fire retarded and a fire retarded flexible polyurethane foam with phosphorus and brominated additives. Journal of Fire Sciences 2001; 19 (2): 137-156. 